Original Research Paper

\title{
Prescription Pattern of Anti-Hypertensive Drugs in Adherence to JNC- 7 Guidelines
}

\author{
${ }^{1}$ Krishna Murti, ${ }^{1}$ M. Arif Khan, ${ }^{1}$ Akalanka Dey, ${ }^{1}$ Manoj Kumar Sethi, ${ }^{2}$ Pradeep Das and ${ }^{3}$ Krishna Pandey \\ ${ }^{I}$ Department of Pharmacy Practice, National Institute of Pharmaceutical Education and Research, Hajipur, India \\ ${ }^{2}$ Department of Molecular Biology, Rajendra Memorial Institute of Medical Sciences, Patna, India \\ ${ }^{3}$ Department of Clinical Medicine, Rajendra Memorial Institute of Medical Sciences, Patna, India
}

\author{
Article history \\ Received: 25-03-2015 \\ Revised: 28-04-2015 \\ Accepted: 25-05-2015 \\ Corresponding Author: \\ Krishna Murti \\ Department of Pharmacy \\ Practice, National Institute of \\ Pharmaceutical Education and \\ Research, Hajipur, India \\ Tel: +91-8969304233 \\ Email: krishnamurti74@yahoo.co.in
}

\begin{abstract}
The main objective of the present study to investigate the utilization pattern of antihypertensive drugs in hypertensive patients and to find out whether the prescription pattern is in adherence with the JNC7 guidelines for the management of hypertension. A prospective study was conducted and drug utilization data were collected from 137 hypertensive patients who were attended as Out Patient Department (OPD) of Rajendra Memorial Research Institute of Medical Sciences (RMRIMS), Patna, Bihar, India. The data was retrieved from patient's medical records as well as from the interview of patients and their legally acceptable representatives. The following classes of antihypertensive drugs were analyzed; Angiotensin Converting Enzyme Inhibitors (ACEI), Angiotensin Receptor Blockers (ARBs), Beta Blockers (BBs), Calcium Channel Blockers (CCBs) and Diuretics. The inclusion criteria for the recruitment of study subjects were the patients suffering from hypertension with or without other comorbid conditions. The analysis of the prescription frequency, proportion of the different antihypertensive classes of drugs as monotherapy as well as combination therapy was done. The most frequently prescribed classes of antihypertensive medications were Diuretics (mainly thiazides followed by Loop category) followed by CCBs, BBs, ACEIs and ARBs. Antihypertensive drug combination therapy was given to $72.26 \%$ of the total population while monotherapy was received by $27.73 \%$ of the total hypertensive population, representing more utilization of combination therapy as compared to monotherapy. The prescription pattern of these classes of drugs was found to be considerately in adherence to JNC7 guidelines for the management of hypertension. It was evident from the study that hypertension is more pronounced in males with increasing age as compared to females. The diuretics were the first choice alone or in combination and pattern of prescription was adhered to JNC-7 Guidelines.
\end{abstract}

Keywords: Drug Utilization, Prescription Pattern, Antihypertensive Drugs, JNC 7

\section{Introduction}

Worldwide the estimates for prevalence of hypertension, to a large extent as 1 billion individuals and approximately around 7.1 million deaths per year may be attributable to hypertension (JNC 7, 2003). Data from the National Health and Nutrition Examination Survey (NHANES) has suggested that 50 million or more Americans are suffering from high Blood Pressure (BP) demanding some form of treatment (Burt et al., 1995; JAMA, 1997). Hypertension is one of the leading contributing factor to many other diseases including Myocardial Infarction (MI), stroke, heart failure, renal failure and retinopathy, a leading cause of death also. In 2004, an estimated 55,000 deaths were directly attributable to hypertension and it was also considered as an underlying cause in other 300,000 deaths (Rosamond et al., 2008). The report of World Health Organization 2002 states that high blood pressure is the primary or may be secondary cause in some cases for $50 \%$ of cardiovascular diseases and subsequent deaths worldwide (Guilbert, 2003). A wide class of 
antihypertensive drugs is available for treatment, with the choice of drug depending upon patient and related factors. Recommendations of various guidelines are available for their treatment, one such guideline is JNC 7 which recommends the rationale administration of drugs by providing algorithms for the treatment as per the stages of hypertension. JNC 7 recommends that for initial stage hypertension Thiazide group of drugs, alone or in combination of drug of choice as well as for the second stage hypertension two drug regimens should be preferred, including one as Thiazide diuretics. Considering the above factors, the following study was designed to analyze the prescribing patterns of antihypertensive drugs and to determine the adherence to JNC 7 guidelines in an Out Patient Department in a research hospital in Patna, India. The purpose of JNC 7 report guidelines is to amalgamated the available scientific evidences and offer guidance to burdened primary care Clinicians.

\section{Material and Methods}

The prospective analysis of the drug utilization pattern of the antihypertensive medications was done in patients satisfying the inclusion criteria. The prescription data was obtained from the Out Patient Department (OPD) of Rajendra Memorial Research Institute of Medical Sciences (RMRIMS), a research hospital in Patna, (Bihar), North India. The study included four months data (Sep. 2013 to Dec 2013). Prescriptions of hypertensive patients along with co morbidities such as Diabetes, risk of cardiovascular diseases, chronic kidney disease and Bronchial asthma were also included in the study.

The age, sex, body weight, height, locality, duration of illness etc. was recorded. Mean age of the patients, sex ratio, obesity ratio (males and females) of the total patients was calculated. The criterion for obesity was satisfied by applying the Ideal Body Weight (IBW) formula for men and women which is given below:

- $\operatorname{IBW}(\mathrm{men})=50 \mathrm{~kg} \pm 1 \mathrm{~kg} / 2.5 \mathrm{~cm}$ above or below $150 \mathrm{~cm}$ in height (Brahmankar and Sunil, 2009)

- $\quad \mathrm{IBW}$ (women) $=45 \mathrm{~kg} \pm 1 \mathrm{~kg} / 2.5 \mathrm{~cm}$ above or below $150 \mathrm{~cm}$ in height (Brahmankar and Sunil, 2009)

Any person whose body weight was more than $25 \%$ above the IBW was considered obese. The patients were classified in accordance to three different age groups; $<40$ years, in between 40-60 years, > above 60 years of age (Fig. 2). The JNC7 guideline adherence for the management of hypertension was studied by taking into consideration that the drugs recommended as the first line therapy by JNC7 should be the most frequently prescribed classes of drugs and should have high utilization pattern among the patients. The information about the drug prescribing pattern was derived from the patient's medical record as well as from the interview of the patients and their representatives.

\section{Results}

The results of this analysis suggests that out of the total 137 hypertensive patients included in the study, 98 patients $(71.5 \%)$ were males while 39 patients $(28.5 \%)$ were females, indicating the higher prevalence of hypertension in male population than in female population, that is $43 \%$ higher prevalence in males than in females. Mean age of males was found to be 58.47 years while of females was 52.39 years. The male and female ratio was calculated to be $2.5: 1$. Out of the total study subjects, $78(56.93 \%)$ were found to be obese with male and female obesity percentage as $17.51 \%$ (24 Male) and $39.41 \%$ (54 Female) respectively (Table 1). The criteria for obesity was defined as per the IBW formula for men and women as discussed above in the methodology segment of this text.

The highest number of male hypertensive patients 48 (35.03\%) belonged to the age group of 40-60 years while the highest number of female hypertensive patients 17 $(12.40 \%)$ belonged to the age group of above 60 years suggesting the earlier onset of hypertension in males than in females in this particular area where the study has been conducted (Table 2).

Out of the total study subjects, 43 (31.38\%) hypertensive patients were found to have other co morbid conditions. Among the total 43 co morbid patients, $22(16.05 \%)$ were found to be diabetic, 7 $(5.10 \%)$ patients were observed at risk of cardiovascular diseases, 12 (8.75) patients were found to have Chronic kidney disease while $2(1.45 \%)$ patients were found to be suffering from bronchial asthma or related respiratory conditions (Table 3 ).

Considering out of the total 137 patients, 38 (27.73\%) patients were received monotherapy (Table 4) while the majority of the patients $99(72.26 \%)$ were put on multidrug therapy (Table 5) with 68 (68.68\%) patients on 2 drug therapy, $27(27.27 \%)$ patients on Three drug therapy and 4 (4.04\%) on Four drug therapy. Among the monotherapy category the various hypertensive classes prescribed were ranked as follows; diuretics $28.94 \%$, followed by CCBs 23.685 , ACEIs and BBs $18.42 \%$ and lastly ARBs $10.52 \%$. As a monotherapy Amlodipine (21.72\%) was the most frequently prescribed drug as monotherapy along with Thiazides (19.67\%), Metoprolol (18.36\%), Ramipril (15.84\%) and Telmisartan $(12.93 \%)$. However in the case of overall utilization pattern of antihypertensive agents, diuretics were the most frequently prescribed class of drugs, ranking first here also, followed by $\mathrm{CCBs} 26.16 \%$, BBs $25.23 \%$, ACEIs $22.42 \%$ and finally ARBs $17.75 \%$. 
Krishna Murti et al. / American Journal of Pharmacology and Toxicology 2015, 10 (1): 27.31 DOI: $10.3844 /$ ajptsp.2015.27.31

Table 1. Demographic details of the patients

\begin{tabular}{|c|c|c|c|c|c|c|c|c|}
\hline \multicolumn{3}{|c|}{ Total no. of patients $(n=137)$} & \multirow{2}{*}{$\begin{array}{l}\text { Male } \\
\text { female ratio } \\
\text { (M:F ratio) }\end{array}$} & \multicolumn{2}{|c|}{ Obese patients $(\mathrm{n}=78)$} & \multicolumn{2}{|c|}{ Mean age of the Patients } & \multirow[b]{2}{*}{ Source of data } \\
\hline Sex & & Percentage & & Total & $(\%)$ & Male & Female & \\
\hline & & & & 78 & $56.98 \%$ & & & $\begin{array}{l}\text { OPD of RMRIMS, } \\
\text { Patna (Bihar), India }\end{array}$ \\
\hline Male & 98 & 71.50 & $2.5: 1$ & 24 & $17.51 \%$ & 58.47 & 52.39 & \\
\hline Female & 39 & 28.50 & & 54 & $39.41 \%$ & & & \\
\hline
\end{tabular}

Table 2. Age distribution of patients

\begin{tabular}{|c|c|c|c|c|c|c|}
\hline \multirow[b]{3}{*}{ Sex } & \multicolumn{6}{|c|}{ Age groups among the patients } \\
\hline & \multicolumn{2}{|c|}{40 years } & \multicolumn{2}{|c|}{$40-60$ years } & \multicolumn{2}{|c|}{ above 60 years } \\
\hline & Total & $(\%)$ & Total & $(\%)$ & Total & $(\%)$ \\
\hline Male & 15 & 10.94 & 48 & 35.03 & 35 & 25.54 \\
\hline Females & 07 & 5.10 & 15 & 10.94 & 17 & 12.40 \\
\hline
\end{tabular}

Table 3. Distribution of patients with co morbidities

\begin{tabular}{|c|c|c|c|c|}
\hline Comorbidities & Male & Female & Total & Percentage \\
\hline \multicolumn{5}{|l|}{$(n=43) 31.35 \%$} \\
\hline Diabetes & 14 & 08 & 22 & 16.05 \\
\hline CVD & 04 & 03 & 07 & 5.10 \\
\hline CKD & 09 & 03 & 12 & 8.75 \\
\hline Bronchial asthma & 00 & 02 & 02 & 1.45 \\
\hline
\end{tabular}

Table 4. Utilization pattern of antihypertensive class of drugs as monotherapy and overall drug therapy Prescription frequency $(\%)$

\begin{tabular}{lll} 
Antihypertensive class & Overall $(\%)$ (comb. therapy) & Monotherapy $(\mathbf{0})$ \\
\hline Diuretics & $32(29.90 \%)$ & $11(28.94 \%)$ \\
ACE Inhibitors & $24(22.42 \%)$ & $07(18.42 \%)$ \\
ARBs & $19(17.75 \%)$ & $04(10.52 \%)$ \\
BBs & $27(25.23 \%)$ & $07(18.42 \%)$ \\
CCBs & $28(26.16 \%)$ & $09(23.68 \%)$ \\
\hline
\end{tabular}

Table 5. Utilization pattern of antihypertensive drug combination therapy

\begin{tabular}{|c|c|c|c|}
\hline \multirow[b]{2}{*}{$\begin{array}{l}\text { Combination } \\
\text { drug regimen }\end{array}$} & \multicolumn{3}{|c|}{ Total prescriptions } \\
\hline & $\begin{array}{l}\text { No. of } \\
\text { prescriptions }\end{array}$ & $\begin{array}{l}\text { Percentage } \\
\text { of total prescriptions }\end{array}$ & $\begin{array}{l}\text { Percentage taking } \\
\text { combination therapy }\end{array}$ \\
\hline \multicolumn{4}{|l|}{ Two Drug Regimen } \\
\hline $\mathrm{CCBs}+\mathrm{BBs}$ & 26 & 18.97 & 26.26 \\
\hline ARBs/ACEIs + Diuretics & 12 & 08.75 & 12.12 \\
\hline ARBs/ACEIs + CCBs & 07 & 05.10 & 07.07 \\
\hline ACEIs + BBs & 05 & 03.64 & 05.05 \\
\hline CCBs + Diuretics & 18 & 13.13 & 18.18 \\
\hline Total no. of prescriptions & 68 & 49.63 & 68.68 \\
\hline \multicolumn{4}{|l|}{ Three Drug Regimen } \\
\hline ACEIs/ARBs + BBs + CCBs & 06 & 04.37 & 06.06 \\
\hline ACEIs/ARBs + BBs + Diuretics & 12 & 08.78 & 12.12 \\
\hline ACEIs/ARBs + CCBs + Diuretics & 09 & 06.56 & 09.09 \\
\hline Total no. of prescriptions & 27 & 19.70 & 27.27 \\
\hline
\end{tabular}

Out of the total (137) population, 38 (27.73\%) patients were received mono drug therapy (Table 4) while $99(72.26 \%)$ patients received combination drug therapy with $68(68.68 \%)$ receiving 2 drug therapy, 27 (27.27\%) receiving 3 drug therapy and 4 (4.04\%) receiving 4 drug therapy. The most frequently prescribed 2 drug regimen was a combination therapy of $\mathrm{CCB}+\mathrm{BB}$ $(18.97 \%)$ while the most frequently prescribed 3 drug regimen was found to be a combination therapy of $\mathrm{ACEI} / \mathrm{ARB}+\mathrm{BB}+\operatorname{Diuretic}(8.75 \%)$ (Fig. 1). 


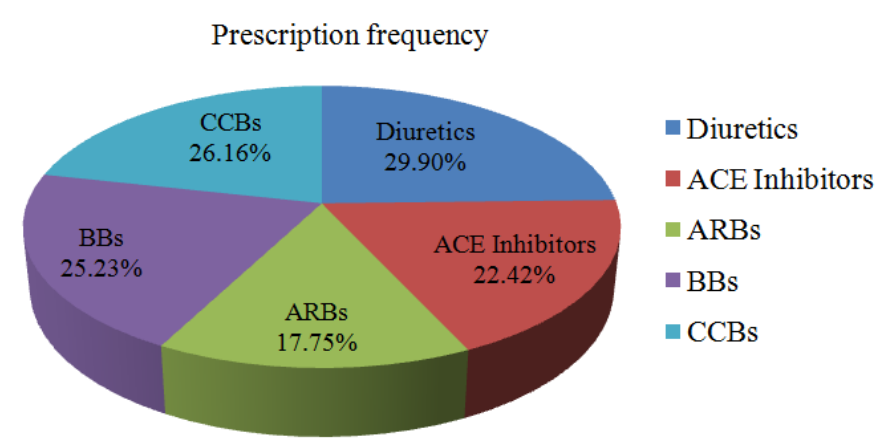

Fig. 1. Pie chart representing prescription frequency of various classes of antihypertensive drugs

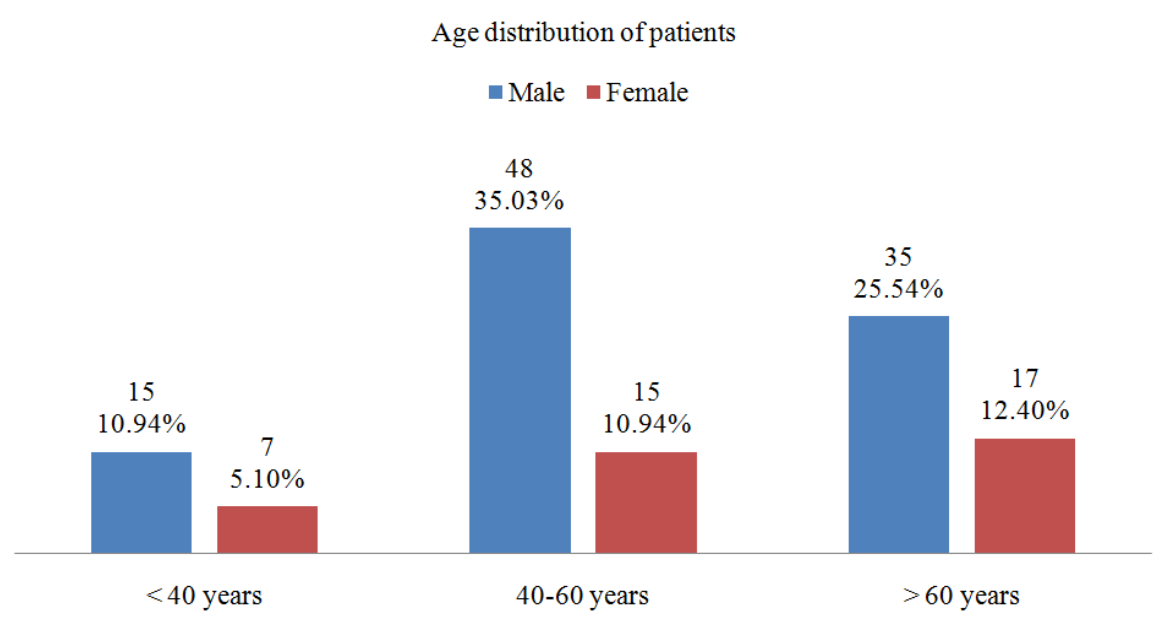

Fig. 2. Bar diagram representing the age distribution of patients

The prescription pattern of these antihypertensives were found to be considerately in adherence to the seventh report of Joint National Committee (JNC 7) for the prevention, detection, evaluation and treatment of hypertension, which recommends that the choice of treatment for initial hypertension i.e., stage I (B.P $>20 / 10$ $\mathrm{mm}$ of $\mathrm{Hg}$ than the normal pressure) should be thiazides for most of the cases, ARBs, ACEIs, CCBs, BBs, alone or in combination may also be preferred, whereas for stage II(B.P $>40 / 20 \mathrm{~mm}$ of $\mathrm{Hg}$ than the normal pressure) hypertension two drug combination, one as thiazides should be preferred. Interview of patients and their representatives suggested that patient compliance to the medication was moderate and was better in females as compared to males.

\section{Discussion}

The results of this study suggests that hypertension is more prevalent in males $(71.5 \%)$, compared to females $(28.5 \%)$. The above pattern is analogous to studies conducted by (Jhaj et al., 2001; Malhotra et al., 2001) in India. However the above pattern is anomalous to other studies conducted by (Tiwari et al., 2004) in India, Pittrow et al. (2004) in Germany and (Lee et al., 1997) in China have reported higher prevalence of hypertension in females than in males. This study also reveals that hypertension is more prevalent in elderly patients belonging to age group 40-60 or more. It also shows that most frequently prescribed classes of drugs are Thiazides alone or in combination. Since the seventh report of Joint National Committee (JNC 7) on detection, evaluation prevention and treatment recommends (Chobanian et al., 2003) the use of Thiazides diuretic for the management of early stage hypertension alone or in combination with other classes, thus suggesting that the above trend is in conformity to the recommendations of JNC 7 guidelines. Hence this drug utilization data corroborates adherence to JNC 7 guidelines. Among the two drug regimen, $\mathrm{CCBs}+\mathrm{BBs}$ is the most widely prescribed regimen (26.26\%), while ACEIs/ARBs + BBs + Diuretics was the most frequently prescribed three drug regimen $(12.12 \%)$.

\section{Conclusion}

This study concludes that hypertension is more prevalent in males than in females, with its prevalence increasing with age. Thiazides are the most frequently prescribed classes of drugs alone or in combination, 
supporting the medication adherence to JNC guidelines. Since the prevalence of hypertension depends upon ethnicity, genetic, environmental and physiological factors, therefore further research is critically needed to set up a rationale or pattern for the choice of medication; on the basis of above mentioned factors.

\section{Acknowledgement}

The authors acknowledge Dr. Pradeep Das, Director, RMRIMS, Patna for his kind support and allowing the project survey to be carried out at RMRIMS, Patna, Bihar, India. We thank Dr. Krishna Pandey (Clinician) for his overall guidance and cooperation in the study. The authors are also thankful to Dr. Akalanka Dey, Professor for their valuable support.

\section{Conflict of Results}

We declare that we have no conflict of interest.

\section{Author's Contributions}

Krishna Murti: Manuscript preparation.

M. Arif Khan: Collected data.

Akalanka Dey: Development of manuscript.

Manoj Kumar Sethi: Data compilation.

Pradeep Das: Guidance for manuscript.

Krishna Pandey: Principal investigator.

\section{Ethics}

This article is original and contains unpublished material. The corresponding author confirms that all of the other authors have read and approved the manuscript and no ethical issues involved.

\section{References}

Brahmankar, D.M. and B. Sunil, 2009. JaiswalBiopharmaceutics and Pharmacokinetics. 2nd Edn., pp: 378.

Burt, V.L., J.A. Cutler, M. Higgins, M.J. Horan and D. Labarthe et al., 1995. Trends in the prevalence, awareness, treatment and control of hypertension in the adult US population data from the health examination surveys, 1960 to 1991. Hypertension, 26: 60-69. DOI: 10.1161/01.HYP.26.1.60
Chobanian, A.V., G.L. Bakris, H.R. Black, W.C. Cushman and L.A. Green et al., 2003. The seventh report of the joint national committee on prevention, detection, evaluation and treatment of high blood pressure. JAMA, 289: 2560-2571. DOI: $10.1001 /$ jama.289.19.2560

Guilbert, J.J., 2003. The world health report 2002: Reducing risks, promoting healthy life. Educ. Health, 16: 230-230.

JAMA, 1997. The sixth report of the joint national committee on prevention, detection, evaluation and treatment of high blood pressure. Arch. Int. Med., 157: 2413-2446.

DOI: 10.1001/archinte.1997.00440420033005

Jhaj, R., N.K. Goel, C.S. Gautam, D. Hota and B. Sangeeta et al., 2001. Prescribing patterns and cost of antihypertensive drugs in an internal medicine clinic. Ind. Heart J., 53: 323-327. PMID: 11516032

Lee, P.K., R.K.L. Li, J.C.N. Chan, S. Chang and S.C. Lee et al., 1997. A prescription survey in a hospital hypertension outpatient clinic. Br. J. Clin. Pharmacol., 44: 577-582. DOI: 10.1046/j.1365-2125.1997.t01-1-00621.x

Malhotra, S., R. Karan, P. Pandhi and S. Jain, 2001. Pattern of use and pharmacoeconomic impact of antihypertensive drugs in a North Indian referral hospital. Eur. J. Clin. Pharmacol., 57: 535-540. DOI: $10.1007 / \mathrm{s} 002280100333$

Pittrow, D., W. Kirch, P. Bramlage, H. Lehnert and M. Höfler et al., 2004. Patterns of antihypertensive drug utilization in primary care. Eur. J. Clin. Pharmacol., 60: $135-142$.

Rosamond, W., K. Flegal, K. Furie, K. Furie and A. Go et al., 2008. Heart disease and stroke statistics 2008 update: A Report from the American heart association statistics committee and stroke statistics subcommittee. Circulation, 117: e25-e146. DOI: $10.1161 /$ CIRCULATIONAHA.107.187998

Tiwari, H., A. Kumar and S.K. Kulkarni, 2004. Prescription monitoring of anti-hypertensive drug utilisation at the Panjab University Health Centre in India. Singapore Med. J., 45: 117-120.

PMID: 15029413 